\title{
Different predictors after stroke depending on functional dependency at discharge: a 5 -year follow up study
}

\author{
Emma Westerlind, Daniel Hörsell and Hanna C. Persson * (1)
}

\begin{abstract}
Background: Level of dependency after a stroke is important for long-term outcome in several aspects, but less is known about important predictors for outcome depending on functional dependency. The aim of the current study was to investigate self-perceived outcome and identify possible predictors of strength, participation, and emotional outcome 5 years after stroke based on functional dependency at discharge from hospital.

Methods: This observational cohort study included participants living in Gothenburg that were diagnosed with first ever stroke in 2009 and 2010. Baseline data were gathered from medical charts and the outcome was based on the Stroke Impact Scale (SIS) questionnaire mailed out 5 years post-stroke. Logistic regression identified potential predictors of better strength, participation, and emotional outcome.

Results: A total of 266 participants responded to the SIS. The functionally independent participants at hospital discharge reported significantly better scores in all SIS domains compared to the functionally dependent. For those who were functionally independent, only non-modifiable factors (age, sex, stroke type) were significant predictors of a better outcome. However, for the functionally dependent participants, modifiable factors such as feeling depressed, cardiovascular risk factors, and recurrent stroke were significant predictors of unfavourable outcome.

Conclusions: Important factors for predicting a favourable outcome differed due to the level of functional dependency, and modifiable factors were only present in participants that were functionally dependent at discharge. Prevention, detection, and treatment of modifiable factors give an opportunity to reduce the burden of stroke for those who are most vulnerable.
\end{abstract}

Keywords: Stroke, Stroke impact scale, Follow-up studies, Rehabilitation

\section{Background}

Stroke is the second largest cause of death worldwide and the third largest cause of disability adjusted life years [1]. In high-income countries such as Sweden, mortality from stroke decrease, while the incidence of stroke increase in low and middle-income countries $[2,3]$. This, in combination with an ageing and growing population,

\footnotetext{
* Correspondence: hanna.persson@neuro.gu.se

Institute of Neuroscience and Physiology, Department of Clinical Neuroscience, Sahlgrenska Academy, Sahlgrenska University Hospital, Per Dubbsgatan 14, 41345 Gothenburg, Sweden
}

has resulted in a substantial increase in persons living with stroke $[1,4]$. The consequences of a stroke are diverse and can depend on factors such as type of stroke, affected brain area, age, comorbidities and time to treatment [5-7]. The subsequent disability may not only be physical, but can also involve cognitive [8] and psychological problems [9]. Although most motor recovery after stroke seems to occur within the first 3 months [10], improved function and activity as well as improved self-perceived outcome has also been reported later [11]. However, a decline in self-perceived outcome within the

C C The Author(s). 2020 Open Access This article is licensed under a Creative Commons Attribution 4.0 International License, which permits use, sharing, adaptation, distribution and reproduction in any medium or format, as long as you give appropriate credit to the original author(s) and the source, provide a link to the Creative Commons licence, and indicate if changes were made. The images or other third party material in this article are included in the article's Creative Commons licence, unless indicated otherwise in a credit line to the material. If material is not included in the article's Creative Commons licence and your intended use is not permitted by statutory regulation or exceeds the permitted use, you will need to obtain permission directly from the copyright holder. To view a copy of this licence, visit http://creativecommons.org/licenses/by/4.0/ The Creative Commons Public Domain Dedication waiver (http://creativecommons.org/publicdomain/zero/1.0/) applies to the data made available in this article, unless otherwise stated in a credit line to the data. 
first year has been shown $[11,12]$. In the long-term perspective, there has also been reported a decline within 6 years [13], with the most affected areas being strength, hand function, and participation [13]. Concerning cognitive impairment, a previous study have shown a potential recovery between 3 months and 3 years post-stroke, even though cognitive impairment substantially occur at both time points [14].

Comorbidities such as atrial fibrillation, diabetes, and previous myocardial infarction of the person with stroke, has been shown to affect functional dependency [6]. More severe stroke [6] and older age [15] seem to additionally predict an unfavourable outcome after stroke. Being a woman has shown to be a risk factor for a higher degree of dependence, institutionalisation, depression, and unfavourable outcome post-stroke $[16,17]$. Suggested explanations for this are that women generally are older and frailer at stroke onset [18], and that women have less support from their spouses and more often live alone [19]. Women seem to receive fewer diagnostic and therapeutic interventions than men after a stroke even when the risks and benefits of the interventions are the same [20]. Depression is common after stroke, nearly one out of four persons that had a previous stroke showed signs of depression in a population based study [21]. Post-stroke depressive symptoms, functional symptoms, functional independency, and lower health related quality of life are correlated to each other, indicating that treating depression is important after a stroke [19].

The initial stroke severity as well as age are strong predictors of long-term functional outcome [22, 23]. However, there is lack of knowledge regarding which specific factors, dependent on the initial functional dependency at discharge, that contribute to recovery. The aim of the study was to investigate self-perceived outcome, as well as identify possible predictors of strength, participation, and emotional outcome 5 years after stroke based on functional dependency at discharge from hospital.

\section{Methods}

This is an observational cohort study with a 5-year follow-up post-stroke. The STROBE-guidelines for observational studies were followed. Data was extracted from the extended Stroke Arm Longitudinal study at the University of Gothenburg (SALGOT-extended) [24-26]. Participants resident in the Gothenburg urban area (within $35 \mathrm{~km}$ from the Sahlgrenska University Hospital), 18 years or older, admitted with a first time ischemic stroke (I63), intra cerebral haemorrhage (I61) or nontraumatic subarachnoid haemorrhage (I60) during 18 months in 2009-2010 at the neurosurgical clinic, stroke unit or the intensive care unit at the largest of the three hospitals creating Sahlgrenska University Hospital were eligible for inclusion in the present study. The Sahlgrenska University Hospital is the only centre in the area that provides interventions such as thrombectomy and thrombolysis.

Five years after stroke, the survivors received a questionnaire survey by mail. The survey included the Swedish version of the Stroke Impact Scale (SIS) 3.0 and the annual follow-up questionnaire from the Swedish Stroke Register. Only participants who replied to any of the SIS-questions were eligible for inclusion in the current study.

Baseline data from the acute phase were collected from medical charts. The National Institutes of Health Stroke Scale (NIHSS) [27] and the Hunt and Hess scale $(\mathrm{H} \& \mathrm{H})[28]$ were assessed by medical doctor at hospital arrival. The NIHSS measures severity of neurological symptoms in ischemic stroke and intra cerebral haemorrhage and the scale range from 0 to 46 , where a lower score is better. In the present study, a score of $0-2$ was considered as very mild stroke, $3-4$ as mild, $5-15$ as moderate and $>16$ as severe stroke. The $\mathrm{H} \& \mathrm{H}$ is used to assess severity of the subarachnoid haemorrhage. The $\mathrm{H} \& \mathrm{H}$ consists of five grades where a lower score suggests a less clinically severe presentation. The modified Rankin Scale (mRS) were assessed at discharge from hospital and was used to assess a person's level of functional dependency. The mRS range from 0 to 5 , and in the current study a dichotomisation of the mRS score was used where $0-2$ represents functional independency and 3-5 functional dependency $[29,30]$. Cardiovascular disease (CVD) was considered as cardiac arrhythmias, coronary artery disease, heart failure, heart valve disease, or septal defects. Cardiovascular risk factor (CVR) was considered as CVD, diabetes, hypertension, or hyperlipidaemia.

\section{Questionnaires follow-up}

The current study includes two questions from the annual Swedish Stroke Register questionnaire. Have you suffered a new stroke, with the answers yes or no. The second question, Do you feel depressed? has five possible answers which was dichotomised as followed: never/almost never/sometimes corresponding to not feeling depressed and often/all the time as feeling depressed [31].

The SIS questionnaire $[32,33]$ captures different aspects of stroke outcome and consists of 59 items in eight domains with questions rated in an ordinal scale 1-5 covering: strength, memory and thinking, mood and emotion control, communication and language, activities of daily living (ADL), mobility, hand function, and participation. Each domain score were then transformed using the following equation: domain score $=($ mean item score-1)/5-1 $\times 100$, with each domain receiving a final total score out of 100 [32, 33]. The composite physical 
domain (including strength, hand function, mobility and ADL) were used [32, 33]. If a participant responded to less than $50 \%$ of the items in a domain, the results from the domain were excluded. The SIS-domain scores were dichotomised in the regression analysis, with scores $\geq 80$ considered as full function [34]. The SIS includes in addition a visual analogue scale (VAS) estimates the respondents self-perceived recovery from 1 to 100 , a higher score is better.

\section{Statistical methods}

All analyses were performed using IBM SPSS version 25.0. For analysing group differences, Mann-Whitney $U$ test and Fischer's exact test were used. Significance level was set to $p<0.05$, two-tailed tests were used.

Based on the level of functional dependency (mRS), logistic regression analysis was used to; predict favourable outcome in each of the dichotomised SIS-domains: emotion, participation and composite physical. Potential predictor variables in each of the models were: recurrent stroke, feeling depressed, sex, age, stroke type, and CVR. Predictor variables were excluded prior to the multivariable analysis if: too few participants $(<5)$ in each subgroup, correlated rho $>0.7$ or $<-0.7$ to other predictors, or if the contribution of the predictor variables were non-significant ( $p$-value $\geq 0.25)$ in univariable regressions. Goodness of fit and accuracy of the multivariable regressions were tested using the Hosmer and Lemeshow test, the Nagelkerke $\mathrm{R}^{2}$, and a Receiver Operating Characteristic (ROC)-curve. An area under the curve (AUC) of $>0.7$ was considered acceptable accuracy, $>0.8$ as excellent and $>0.9$ as outstanding.

\section{Results}

Of the 457 persons that were alive 5 years post stroke, 266 persons (58\%) responded to the SIS questionnaire in the follow-up survey (Fig. 1). There were no significant differences regarding age $(p=0.397)$, functional dependency at discharge from hospital $(p=0.145)$, aphasia at stroke onset $(p=1.0)$ or side of lesion $(p=0.107)$ between the responders $(n=266)$ and the non-responders $(n=191)$ to the follow-up questionnaires. However, there were significantly more females in the non-responders group (non-responders female $n=103$ (53\%), responders female $n=101(38 \%), p=0.001)$. As well as non-responders had longer length of stay in the hospital (mean (SD) 11.1 (13.78) compared to, $8.3(8.03) p=0.0005)$.

The majority of the participants were men, the mean age at the time of stroke was 65 years and most of the participants had a very mild stroke (Table 1). About half of the participants were functionally independent at discharge from hospital (Table 1). The participants that were functionally dependent at hospital discharge had a more severe stroke at onset (NIHSS and $\mathrm{H} \& \mathrm{H}$ ). At 5 year post stroke, participants that were functionally dependent at discharge, reported a higher prevalence of feeling of depressed, 19\% (25/136), compared to 9\% (11/ 130) in participants that were functionally independent (Table 1).

At 5 years post stroke (mean 4,9 SD 0.50), the participants reported a median of 88-95 in all of the domains of SIS except for the strength domain (median 75) and the emotion domain (median 69) (Table 2). The participants that were functionally independent at discharge from hospital reported significantly higher scores in all

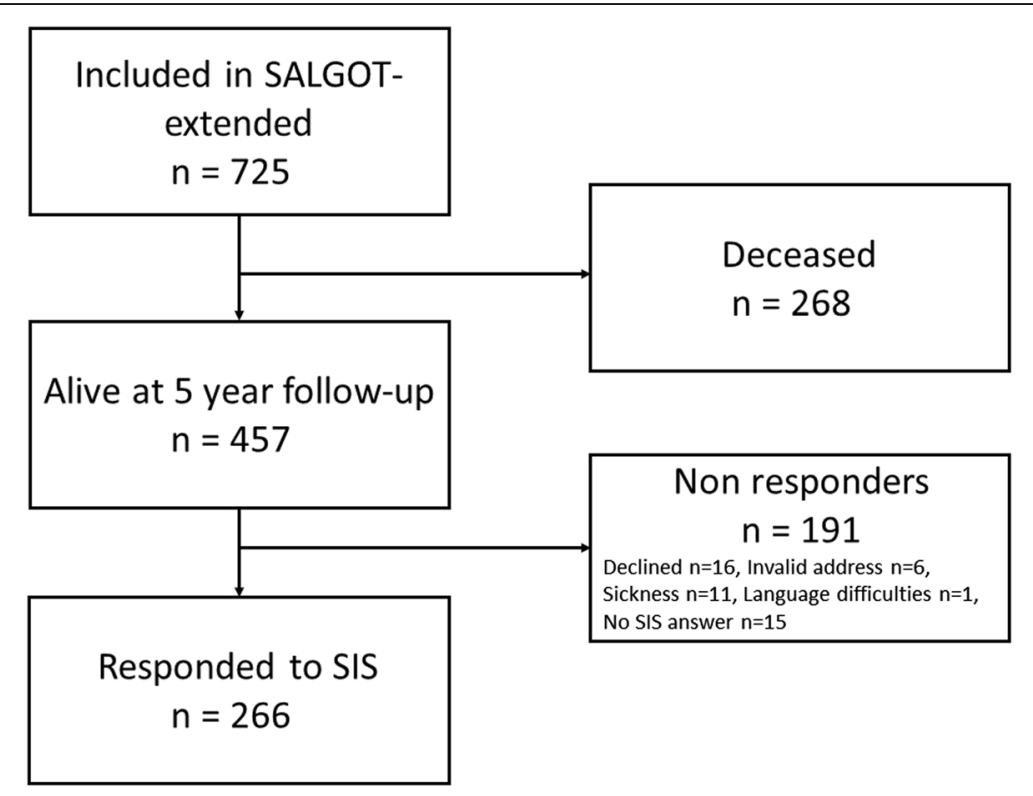

Fig. 1 Flowchart of the inclusion process 
Table 1 Demographic and clinical characteristics at baseline and 5 years post-stroke, divided according to functional dependency at discharge from hospital

\begin{tabular}{|c|c|c|c|}
\hline & All participants & Functionally independent & Functionally dependent \\
\hline Total, n (\%) & $266(100)$ & $130(49)$ & $136(51)$ \\
\hline \multicolumn{4}{|l|}{ Baseline } \\
\hline Age, mean (SD) & $65(14)$ & $64(13)$ & $66(14)$ \\
\hline \multicolumn{4}{|l|}{ Sex, n (\%) } \\
\hline Male & $163(61)$ & $85(65)$ & $78(57)$ \\
\hline Female & $103(39)$ & $45(35)$ & $58(43)$ \\
\hline \multicolumn{4}{|l|}{ Stroke type, n (\%) } \\
\hline Ischemic stroke & $205(77)$ & $110(85)$ & $95(70)$ \\
\hline Intra cerebral heamorrhage & $34(13)$ & $7(5)$ & $27(20)$ \\
\hline Subarachnoid heamorrhage & $27(10)$ & $13(10)$ & $14(10)$ \\
\hline \multicolumn{4}{|l|}{ Side of lesion ${ }^{\mathrm{a}}, \mathrm{n}(\%)$} \\
\hline Right hemisphere & $95(39)$ & $46(39)$ & $49(39)$ \\
\hline Left hemisphere & $123(51)$ & $57(49)$ & $66(53)$ \\
\hline Bilateral lesion & $7(3)$ & $3(3)$ & $4(3)$ \\
\hline Cerebellum & $4(2)$ & $0(0)$ & $4(3)$ \\
\hline Unknown & $13(5)$ & $11(9)$ & $2(2)$ \\
\hline $\mathrm{NIHSS}{ }^{\mathrm{b}}$, median (min-max) & $1(0-24)$ & $1(0-20)$ & $2(0-24)$ \\
\hline$H \& H^{c}$, median (min-max) & $2(1-5)$ & $2(1-4)$ & $2(1-5)$ \\
\hline Length of hospital stay ${ }^{\mathrm{d}}$, mean (SD) & $8(7)$ & $5(4)$ & $11(8)$ \\
\hline \multicolumn{4}{|l|}{ Comorbidity $^{\mathrm{e}}, \mathrm{n}(\%)$} \\
\hline CVD & $69(26)$ & $31(24)$ & $38(29)$ \\
\hline CVR & $157(60)$ & $54(42)$ & $82(62)$ \\
\hline \multicolumn{4}{|l|}{ Five years post-stroke } \\
\hline \multicolumn{4}{|l|}{ Recurrent stroke, n (\%) } \\
\hline Yes & $41(15)$ & $21(16)$ & $20(15)$ \\
\hline No & $225(85)$ & $109(84)$ & $116(85)$ \\
\hline \multicolumn{4}{|l|}{ Feeling depressed ${ }^{f}, \mathrm{n}(\%)$} \\
\hline Never or almost never/Sometimes & $221(86)$ & $116(91)$ & $105(81)$ \\
\hline Often/always & $36(14)$ & $11(9)$ & $25(19)$ \\
\hline
\end{tabular}

Abbreviations: SD Standard deviation, NHISS National Institutes of Health Stroke Scale, H\&H Hunt and Hess, CVD Cardiovascular disease, CVR Cardiovascular risk ${ }^{\mathrm{a}} n=242 .{ }^{\mathrm{b}} n=215 .{ }^{\mathrm{c}} n=25 .{ }^{\mathrm{d}} n=237^{\mathrm{e}} n=262 .{ }^{\mathrm{f}} n=257$

Table 2 Outcome and recovery in each SIS domain, in all participants, and depending on functionally dependency

\begin{tabular}{|c|c|c|c|c|}
\hline Domain & $\begin{array}{l}\text { All participants, } \\
\text { median (min-max) }\end{array}$ & $\begin{array}{l}\text { Functionally independent, } \\
\text { median (min-max) }\end{array}$ & $\begin{array}{l}\text { Functionally dependent, } \\
\text { median (min-max) }\end{array}$ & $\boldsymbol{P}$-value \\
\hline Strength, $n=234$ & $75(0-100)$ & $100(25-100)$ & $69(0-100)$ & $<0.001$ \\
\hline Hand function, $n=255$ & $95(0-100)$ & $100(10-100)$ & $75(0-100)$ & $<0.001$ \\
\hline Mobility, $n=263$ & $92(0-100)$ & $100(38-100)$ & $86(0-100)$ & $<0.001$ \\
\hline ADL/IADL, $n=265$ & $95(0-100)$ & $100(23-100)$ & $85(0-100)$ & $<0.001$ \\
\hline Physical, $n=222$ & $92(0-100)$ & $98(35-100)$ & $82(0-100)$ & $<0.001$ \\
\hline Emotion, $n=262$ & $69(17-100)$ & $75(28-100)$ & $67(17-100)$ & $<0.001$ \\
\hline Language and communication, $n=263$ & $93(11-100)$ & $96(39-100)$ & $89(11-100)$ & $<0.001$ \\
\hline Participation, $n=258$ & $88(0-100)$ & $97(22-100)$ & $78(0-100)$ & $<0.001$ \\
\hline Memory, $n=255$ & $89(11-100)$ & $93(32-100)$ & $79(11-100)$ & $<0.001$ \\
\hline
\end{tabular}


domains of the SIS compared to participants that were functionally dependent (Table 2). The emotion domain had the lowest scores in both groups. Furthermore, selfperceived recovery according to the VAS (SIS), was higher among the functionally independent participants (median 90) compared with the functionally dependent participants (median 70).

Among the functionally independent participants, higher age was a significant predictor for lower odds of having favourable outcome in the emotion domain (OR 0.938 ) and the physical domain (OR 0.847), Table 3. In the participation domain however, only sex was significant with an OR of 0.351 for females to have a favourable outcome. Stroke type was a significant predictor of emotional outcome, with lower odds of favourable outcome for persons with haemorrage compared to ischaemic stroke (OR 0.251). The emotion and physical domain regression models had an acceptable and excellent accuracy (ROC-curve), however this was not seen in the participation domain model.

As seen in Table 4, for participants that were functionally dependent at discharge, no significant predictor could be found for outcome in the emotion domain. In the physical domain, being female (OR 0.290), having a recurrent stroke (OR 0.257), feeling depressed (OR 0.347), and having CVR (OR 0.347) were all predictors for lower odds of having favourable outcome. In the participation domain, feeling depressed could predict outcome with an OR of 0.227 . The physical regression model had an acceptable accuracy.

\section{Discussion}

As seen in the present study, the level of dependency at discharge from hospital is still of importance in selfperceived outcome 5 years after a stroke. Participants who were functionally independent at discharge from hospital reported significantly more favourable outcome compared to functionally dependent participants. Different factors were important for predicting outcome in the emotional, physical and participation domains, depending on level of functional dependency at discharge from hospital. These new findings highlight the importance of considering the level of functional dependency early after stroke, to be able to give tailored rehabilitation.

Overall, the significant predictor for outcome in the functionally independent participants were all nonmodifiable factors, including sex, age, and stroke type. In the functionally dependent participants, the predictors mainly included modifiable factors, such as recurrent stroke, feeling of depression, and CVR. This indicates that in the functionally dependent participants, it is important to detect, prevent and treat these factors in order to reduce the long term stroke burden. For participants that were functionally dependent at discharge, feeling depressed was a predictor in the physical domain, and the only contributing predictor in the participation domain. Depression has been shown to have a significant relationship to functional outcome after stroke [35] and depression itself is an important risk factor for stroke [36]. Since depression is an at least partly treatable condition, it is important for health care professionals to be aware of its importance for outcome after stroke, so that that the detection and treatment of depression can be optimised.

The CVR and recurrent stroke were significant predictors for outcome in participants that were functionally dependent. The CVR includes heart disease and diabetes, which also could be risk factors for functional restriction. Like myocardial infarction, multiple risk factors combined could cause an acute stroke [37]. Ten potentially modifiable risk factors are associated with $90 \%$ of stroke including untreated hypertension, psychosocial factors, obesity, tobacco smoking, heavy alcohol use, diabetes mellitus, inactive lifestyle, and unhealthy diet [37]. Increased physical activity has both physical and psychological benefits post stroke [38] and regular physical activity prevent a large number of risk factors for cardiovascular diseases [37]. In the present study, participants that were functionally dependent at

Table 3 Multivariable regression of predictors for favourable outcome and recovery in the emotion, physical and participation domain in the SIS questionnaire, for participants that were functionally independent at hospital discharge (mRS 0-2)

\begin{tabular}{|c|c|c|c|c|c|c|}
\hline \multirow[t]{2}{*}{ Functionally independent } & \multicolumn{2}{|l|}{ Emotion } & \multicolumn{2}{|l|}{ Physical } & \multicolumn{2}{|l|}{ Participation } \\
\hline & OR $(95 \% \mathrm{Cl})$ & $p$-value & OR $(95 \% \mathrm{Cl})$ & $p$-value & OR $(95 \% \mathrm{Cl})$ & $p$-value) \\
\hline Stroke type, heamorrhage & $0.251(0.076-0.828)$ & 0.023 & & & & \\
\hline Age & $0.938(0.907-0.971)$ & $<0.001$ & $0.847(0.772-0.929)$ & $<0.001$ & $0.978(0.949-1.009)$ & 0.158 \\
\hline Sex, female & $0.563(0.244-1.298)$ & 0.178 & $0.452(0.114-1.783)$ & 0.257 & $0.351(0.156-0.792)$ & 0.012 \\
\hline Recurrent stroke & & & & & $0.454(0.163-1.264)$ & 0.131 \\
\hline Nagelkerke $\mathrm{R}^{2}$ & 0.198 & & 0.411 & & 0.104 & \\
\hline ROC-curve, AUC & 0.730 & & 0.884 & & 0.666 & \\
\hline Hosmer and Lemeshow test & 0.658 & & 0.997 & & 0.480 & \\
\hline
\end{tabular}

Abbreviations: OR Odds ratio, $\mathrm{Cl}$ Confidence interval, ROC Receiver operating characteristics, AUC Area under the curve 
Table 4 Multivariable regression of predictors for favourable outcome and recovery in the emotion, physical and participation domain in the SIS questionnaire, for participants that were functionally dependent at discharge from hospital (mRS 3-5)

\begin{tabular}{|c|c|c|c|c|c|c|}
\hline \multirow[t]{2}{*}{ Functionally dependent } & \multicolumn{2}{|l|}{ Emotion } & \multicolumn{2}{|l|}{ Physical } & \multicolumn{2}{|l|}{ Participation } \\
\hline & OR $(95 \% \mathrm{Cl})$ & $p$-value & OR $(95 \% \mathrm{Cl})$ & $p$-value & OR $(95 \% \mathrm{Cl})$ & $p$-value) \\
\hline Age & $0.988(0.958-1.018)$ & 0.422 & $0.977(0.941-1.015)$ & 0.229 & $0.975(0.942-1.009)$ & 0.151 \\
\hline Sex, female & $0.408(0.158-1.058)$ & 0.065 & $0.290(0.115-0.728)$ & 0.008 & $0.670(0.298-1.505)$ & 0.332 \\
\hline Recurrent stroke & & & $0.257(0.071-0.922)$ & 0.037 & $0.383(0.117-1.252)$ & 0.112 \\
\hline Feeling depressed & & & $0.311(0.102-0.954)$ & 0.041 & $0.227(0.078-0.658)$ & 0.006 \\
\hline CVR & & & $0.347(0.126-0.956)$ & 0.041 & $0.817(0.319-2.093)$ & 0.673 \\
\hline Nagelkerke $\mathrm{R}^{2}$ & 0.059 & & 0.297 & & 0.173 & \\
\hline ROC-curve, AUC & 0.630 & & 0.756 & & 0.695 & \\
\hline Hosmer and Lemeshow test & 0.473 & & 0.363 & & 0.636 & \\
\hline
\end{tabular}

Abbreviations: OR Odds ratio, CI Confidence interval, ROC Receiver operating characteristics, AUC Area under the curve

discharge from hospital should be a specific target of preventive measures such as increased physical activity and use of medication for treatable conditions. The nonmodifiable predictors, predominantly age and sex, were of importance for predicting outcome. Being female was a predictor of lower odds of favourable outcome in one of the physical models and one of the participation models. Generally women have less muscle mass to compensate deficits, women are generally older at stroke onset as well, which could partly explain the sex differences [39].

Participants had an overall good outcome in all of the SIS domains in the present study, regardless of functional dependency, and lowest scores were present in the emotion domain. Perceived emotion has been shown to be associated with perceived participation [34], and in the present study self-perceived participation was lower in participants that were functionally dependent, also seen previously [13, 40, 41]. It could be hypothesised that increased level of participation after stroke also could improve self-perceived outcome.

\section{Limitations}

The present study has limitations that need to be discussed. The use of SIS gave information about selfperceived outcome after stroke in several aspects of health. The present study did however not contain any diagnostic assessments of for instance depression and anxiety or any information about medication for depression or anxiety, which limits the results. Furthermore, there is missing information about received rehabilitation after stroke, which could affect the results.

Other factors may be of importance for the regression models than the predictors included, indicated by the small AUC of the ROC-curves and pseudo- $\mathrm{R}^{2}$ in some of the regression models. For instance, the study does not have information on the socioeconomic background, educational level, type of work or comorbidities of the participants. The low goodness of fit in some of the models affects the strength of the model, and the results needs to be interpreted with caution.

The relatively low response rate of $58 \%$ could entail a risk of selection bias of the study population. The participants in the present study were more likely to have a subarachnoid haemorrhage, were younger, more often male and had less severe stroke than the general stroke population in Sweden [42]. This could be explained by old and frail patients not surviving the five-year followup to the same extent as younger patients. There were also a lower mortality rate among the people eligible for inclusion in the present study compared to the general Swedish stroke population [43]. Furthermore, the study was performed in an urban setting and at a university hospital with accessibility to interventions such as revascularisation and neurosurgery. This could cause selection bias and needs to be taken into account when generalising the findings.

\section{Conclusion}

Five years post-stroke participants that were functionally independent at discharge had better outcomes in all domains compared to the functionally dependent. Depending on functional dependency at discharge, different predictors were important for a favourable outcome. Functionally independent participants only had non-modifiable predictors, whereas the functionally dependent participants mainly had modifiable predictors. This new information provides an opportunity to improve the situation for the most vulnerable stroke survivors, by providing tailored rehabilitation efforts, as well as preventing and treating risk factors.

\section{Abbreviations}

ADL: Activities of daily living; AUC: Area under the curve; CVD: Cardiovascular disease; CVR: Cardiovascular risk factor; H\&H: Hunt \& Hess; mRS: Modified Rankin Scale; NIHSS: National Institutes of Health Stroke Scale; OR: Odds ratio; 
ROC: Receiver Operating Characteristic; SALGOT: Stroke Arm Longitudinal study at the University of Gothenburg; SIS: Stroke Impact Scale; VAS: Visual analogue scale

\section{Acknowledgements}

We would like to thank all the participants in the study. Professor Katharina Stibrant Sunnerhagen for support and encouragement. We would also like to thank Dr. Kate Bramley-Moore for checking the language of the manuscript.

\section{Authors' contributions}

EW, DH and HCP all contributed to conception and design of the study. HCP acquired the data and obtained funding. $\mathrm{DH}$ analysed and interpreted the data. EW and DH wrote the draft and the revisions of the manuscript, and HCP commented and critically reviewed the manuscript drafts and revisions. All authors read and approved the final manuscript.

\section{Funding}

This work was financially supported by grants from the Swedish Science Council (VR2017-00946), by grants from the Swedish state under the agreement between the Swedish government and the country councils, ALF agreement (ALFGBG-718711), The Swedish Heart-Lung Foundations, The Swedish Brain Foundation, Promobila, The Swedish Stroke Association. Founding bodies did not play any other role than financial support. Open access funding provided by University of Gothenburg.

\section{Availability of data and materials}

The data sets analysed during the current study are not publicly available due to ethical restrictions. According to the Swedish regulation http://www. epn.se/en/start/regulations/, the permission to use data is only for what has been applied for and then approved by the Ethical board. Data are available from the authors (contact Dr. Hanna C. Persson, email: hanna.persson@neuro. gu.se) upon reasonable request.

\section{Ethics approval and consent to participate}

The SALGOT study and the follow-up postal survey were approved by the Regional Ethical Review Board in Gothenburg (Dnr 225-08, T801-10 and Dnr 400-13) and followed the Helsinki declaration. The data in the present study is anonymized and non-identifiable.

No written or verbal consent were obtained, but information was given about the purpose of the follow-up postal survey and that participation and response to the survey was voluntary. Participants could choose to answer all or some of the questions.

The Swedish Data Inspection Board has decided that data handeling within the frame of national quality registers is an exception from the general rule of informed consent because it provides improved quality of care and treatment that is of general interest. Further, for clinical puproses and quality control, no informed consent is needed to collect data from medical charts, according to Swedish law on personal particulars data (personuppgiftslagen, Swedish law No. SFS 1998:204).

\section{Consent for publication}

Not applicable.

\section{Competing interests}

The authors declare that they have no competing interests.

Received: 8 January 2020 Accepted: 24 June 2020

Published online: 01 July 2020

\section{References}

1. Collaborators GBDN. Global, regional, and national burden of neurological disorders, 1990-2016: a systematic analysis for the global burden of disease study 2016. Lancet Neurol. 2019;18(5):459-80.

2. Aked J, Delavaran H, Norrving B, Lindgren A. Temporal trends of stroke epidemiology in southern Sweden: a population-based study on stroke incidence and early case-fatality. Neuroepidemiology. 2018;50(3-4):174-82.

3. Roth GA, Forouzanfar MH, Moran AE, Barber R, Nguyen G, Feigin VL, et al. Demographic and epidemiologic drivers of global cardiovascular mortality. N Engl J Med. 2015;372(14):1333-41.
4. Rosengren WA, Giang WK, Lappas WG, Jern WC, Torén WK, Björck WL. Twenty-four-year trends in the incidence of ischemic stroke in Sweden from 1987 to 2010. Stroke. 2013;44(9):2388-93.

5. Sumer MM, Ozdemir I, Tascilar N. Predictors of outcome after acute ischemic stroke*. Acta Neurol Scand. 2003;107(4):276-80.

6. Fischer U, Arnold M, Nedeltchev K, Schoenenberger RA, Kappeler L, Höllinger $P$, et al. Impact of comorbidity on ischemic stroke outcome. Acta Neurol Scand. 2006;113(2):108-13.

7. Sennfält S, Norrving B, Petersson J, Ullberg T. Long-Term Survival and Function After Stroke [published online ahead of print, 2018 Dec 7]. Stroke. 2018;STROKEAHA118022913. https://doi.org/10.1161/STROKEAHA.118. 022913.

8. Sun J-H, Tan L, Yu J-T. Post-stroke cognitive impairment: epidemiology, mechanisms and management. Ann Transl Med. 2014;2(8):80.

9. Rafsten L, Danielsson A, Sunnerhagen KS. Anxiety after stroke: a systematic review and meta-analysis. J Rehabil Med. 2018;50(9):769-78.

10. Persson HC, Opheim A, Lundgren-Nilsson A, Alt Murphy M, Danielsson A, Sunnerhagen KS. Upper extremity recovery after ischaemic and haemorrhagic stroke: part of the SALGOT study. Eur Stroke J. 2016;1(4):3109.

11. Guidetti S, Ytterberg C, Ekstam L, Johansson U, Eriksson G. Changes in the impact of stroke between 3 and 12 months post-stroke, assessed with the stroke impact scale. J Rehabil Med. 2014;46(10):963-8.

12. Ullberg T, Zia E, Petersson J, Norrving B. Perceived unmet rehabilitation needs 1 year after stroke: an observational study from the Swedish stroke register. Stroke. 2016:47(2):539-41.

13. Ytterberg C, Dybäck M, Bergström A, Guidetti S, Eriksson G. Perceived impact of stroke six years after onset, and changes in impact between one and six years. J Rehabil Med. 2017;49(8):637.

14. Liman TG, Heuschmann PU, Endres M, Flöel A, Schwab S, Kolominsky-Rabas $\mathrm{PL}$. Changes in cognitive function over 3 years after first-ever stroke and predictors of cognitive impairment and long-term cognitive stability: the Erlangen stroke project. Dement Geriatr Cogn Disord. 2011;31(4):291-9.

15. Kammersgaard LP, Jørgensen HS, Reith J, Nakayama H, Pedersen PM, Olsen TS. Short- and long-term prognosis for very old stroke patients. The Copenhagen stroke study. Age Ageing. 2004;33(2):149-54.

16. Reeves MJ, Bushnell CD, Howard G, Gargano JW, Duncan PW, Lynch G, et al. Sex differences in stroke: epidemiology, clinical presentation, medical care, and outcomes. Lancet Neurol. 2008;7(10):915-26.

17. Petrea RE, Beiser AS, Seshadri S, Kelly-Hayes M, Kase CS, Wolf PA. Gender differences in stroke incidence and Poststroke disability in the Framingham heart study. Stroke. 2009;40(4):1032-7.

18. Phan HT, Gall SL, Blizzard CL, Lannin NA, Thrift AG, Anderson CS, et al. Sex differences in care and long-term mortality after stroke: Australian stroke clinical registry. J Women's Health (Larchmt). 2019;28(5):712-20.

19. Abubakar SA, Isezuo SA. Health related quality of life of stroke survivors: experience of a stroke unit. Int J Biomed Sci. 2012;8(3):183-7.

20. Di Carlo A, Lamassa M, Baldereschi M, Pracucci G, Basile AM, Wolfe CDA, et al. Sex differences in the clinical presentation, resource use, and 3-month outcome of acute stroke in Europe: data from a multicenter multinational hospital-based registry. Stroke. 2003;34(5):1114.

21. Broomfield N, Quinn T, Abdul-Rahim A, Walters M, Evans J. Depression and anxiety symptoms post-stroke/TIA: prevalence and associations in crosssectional data from a regional stroke registry. BMC Neurol. 2014;14:198.

22. Kwakkel G, Kollen BJ. Predicting activities after stroke: what is clinically relevant? Int J Stroke. 2013;8(1):25-32.

23. Wouters A, Nysten C, Thijs V, Lemmens R. Prediction of outcome in patients with acute ischemic stroke based on initial severity and improvement in the first 24 h. Front Neurol. 2018;9:308.

24. Persson HC, Parziali M, Danielsson A, Sunnerhagen KS. Outcome and upper extremity function within 72 hours after first occasion of stroke in an unselected population at a stroke unit. A part of the SALGOT study. Bmc Neurol. 2012;12(1):162.

25. Vikholmen K, Persson HC, Sunnerhagen KS. Stroke treated at a neurosurgical ward: a cohort study. Acta Neurol Scand. 2015;132(5):329-36.

26. Wesali S, Persson HC, Cederin B, Sunnerhagen KS. Improved survival after non-traumatic subarachnoid haemorrhage with structured care pathways and modern intensive care. Clin Neurol Neurosurg. 2015;138:52-8.

27. Brott T, Adams HP Jr, Olinger CP, Marler JR, Barsan WG, Biller J, et al. Measurements of acute cerebral infarction: a clinical examination scale. Stroke. 1989;20(7):864-70. 
28. Hunt WE, Hess RM. Surgical risk as related to time of intervention in the repair of intracranial aneurysms. J Neurosurg. 1968;28(1):14-20.

29. Weisscher $N$, Vermeulen $M$, Roos $Y$, Haan R. What should be defined as good outcome in stroke trials; a modified Rankin score of 0-1 or 0-2? J Neurol. 2008;255(6):867-74.

30. Synhaeve EN, Arntz MR, Maaijwee AMN, Rutten-Jacobs CAL, Schoonderwaldt $\mathrm{CH}$, Dorresteijn DAL, et al. Poor long-term functional outcome after stroke among adults aged 18 to 50 years: follow-up of transient ischemic attack and stroke patients and Unelucidated risk factor evaluation (FUTURE) study. Stroke. 2014;45(4):1157-60.

31. Eriksson HM, Asplund HK, Glader HE-L, Norrving HB, Stegmayr HB, Terént $\mathrm{HA}$, et al. Self-reported depression and use of antidepressants after stroke: a National Survey. Stroke. 2004;35(4):936-41.

32. Duncan PW, Wallace D, Lai SM, Johnson D, Embretson S, Laster LJ. The stroke impact scale version 2.0. Evaluation of reliability, validity, and sensitivity to change. Stroke. 1999;30(10):2131-40.

33. Duncan PW, Bode RK, Min Lai S, Perera S. Rasch analysis of a new strokespecific outcome scale: the stroke impact scale. Arch Phys Med Rehabil. 2003;84(7):950-63.

34. Eriksson G, Baum MC, Wolf TJ, Connor LT. Perceived participation after stroke: the influence of activity retention, reintegration, and perceived recovery. Am J Occup Ther. 2013;67(6):e131-e8.

35. Herrmann N, Black SE, Lawrence J, Szekely C, Szalai JP. The Sunnybrook stroke study: a prospective study of depressive symptoms and functional outcome. Stroke. 1998;29(3):618-24.

36. Brunner EJ, Shipley MJ, Britton AR, Stansfeld SA, Heuschmann PU, Rudd AG et al. Depressive disorder, coronary heart disease, and stroke: dose-response and reverse causation effects in the Whitehall II cohort study. Eur J Prev Cardiol. 2014;21(3):340-6.

37. O'Donnell MJ, Chin SL, Rangarajan S, Xavier D, Liu L, Zhang H, et al. Global and regional effects of potentially modifiable risk factors associated with acute stroke in 32 countries (INTERSTROKE): a case-control study. Lancet. 2016;388(10046):761-75.

38. English C, Manns PJ, Tucak C, Bernhardt J. Physical activity and sedentary behaviors in people with stroke living in the community: a systematic review. Phys Ther. 2014;94(2):185-96.

39. Paolucci RS, Bragoni RM, Coiro RP, De Angelis RD, Fusco RF, Morelli RD, et al. Is sex a prognostic factor in stroke rehabilitation?: a matched comparison. Stroke. 2006:37(12):2989-94.

40. Persson HC, Selander H. Transport mobility 5 years after stroke in an urban setting. Top Stroke Rehabil. 2018;25(3):180-5.

41. Norlander A, Carlstedt E, Jonsson AC, Lexell EM, Stahl A, Lindgren A, et al. Long-term predictors of social and leisure activity 10 years after stroke. PLoS One. 2016:11(2):e0149395.

42. Riksstroke (the Swedish Stroke Register). Riks-Stroke - årsrapport 20102011. Available from: http://www.riksstroke.org/wp-content/uploads/2014/05/RiksStroke_\%C3\%85rsrapport2010.pdf. Cited 202016 June 2020.

43. Riksstroke (the Swedish Stroke Register). Fem och tre år efter stroke. 2018.

\section{Publisher's Note}

Springer Nature remains neutral with regard to jurisdictional claims in published maps and institutional affiliations.

Ready to submit your research? Choose BMC and benefit from:
- fast, convenient online submission
- thorough peer review by experienced researchers in your field
- rapid publication on acceptance
- support for research data, including large and complex data types
- gold Open Access which fosters wider collaboration and increased citations
- maximum visibility for your research: over 100M website views per year
At BMC, research is always in progress.
Learn more biomedcentral.com/submissions

